\title{
Ética médica en la práctica clínica
}

\section{Medical ethics in clinical practice}

\author{
Rodolfo F. de Freitas ${ }^{1}$, Francisco A.M. Neto ${ }^{1}$, Marcos A. Fernandes ${ }^{2}$, Josiana M. Mar
}

'Asociación Médica Brasileña

(AMB). Manaus, Brasil.

${ }^{2}$ Asociación Brasileña de

Otorrinolaringología. Manaus,

Brasil.

${ }^{3}$ Laboratorio de Polímeros

Nanoestructurados

(NANOPOL), Universidad

Federal de Amazonas (UFAM)

Manaus, Brasil.

Los autores declaran no tener conflictos de interés.

Recibido el 10 de julio de

2021. Aceptado el 12 de agosto de 2021

Correspondencia:

Josiana M. Mar

Laboratorio de Polímeros

Nanoestructurados

(NANOPOL), Universidad

Federal de Amazonas (UFAM)

Manaus, Brasil.

Email: josimoreira@ufam. edu.br

\section{Resumen}

La actividad médica se puede ver en dos contextos diferentes, tanto en la práctica clínica como en la investigación científica. El concepto de práctica clínica es todo acto realizado sobre un paciente con el objetivo de diagnosticar o tratar enfermedades. Por otro lado, la investigación clínica cuestiona diferentes aspectos relacionados con la salud humana. Este estudio busca inicialmente esclarecer los aspectos y componentes que orientan la relación y comunicación médico-paciente, definiendo los valores éticos de esta práctica, donde el profesional médico modela su carácter, mediante una relación entre los principios abordados en el ámbito de la ética de los profesionales de la salud. La demostración de una adecuada y sana relación de los profesionales médicos con sus pacientes es necesaria y fundamental a través del respeto y principalmente a través del principio de autonomía, ya que todo ser humano debe ser reconocido como fin y dueño de sí mismo, donde las actividades médicas comprenden procesos que involucran vida, salud e integridad física. Así, el presente trabajo abordará los diversos aspectos de la ética médica, en relación con el contexto de la práctica clínica del médico.

Palabras clave: Clínica, práctica médica, moral, salud.

\begin{abstract}
The medical activity can be seen in different contexts, both in clinical practice and in scientific research. The concept of clinical practice is every act performed on a patient with the objective of diagnosing or treating illnesses. On the other hand, clinical research questions different aspects related to human health. This study initially seeks to clarify the aspects and components that guide the doctor-patient relationship and communication, defining the ethical values of this practice, from which the medical professional models its character, through a relationship between the principles addressed in the scope of their ethics. health professionals. The demonstration of an adequate and healthy relationship between medical professionals and their patients is necessary and fundamental through respect and mainly through the principle of autonomy, since every human being must be recognized as an end and duen of symbolism, hence medical activities include processes that involve life, health and physical integrity. Thus, this work will address the various aspects of medical ethics, in relation to the context of the clinical practice of the doctor.
\end{abstract}

Keywords: Clinic, medical practice, moral, health.
La ética podría definirse como la ciencia de la moral. Su importancia va desde una actividad puramente técnica, hasta un proceso que plantea nuevos problemas morales o genera nuevas visiones sobre viejos temas ${ }^{1}$. La moral y la ética son dos conceptos estrechamente relacionados, lo que hace que la interacción médico-paciente asuma el más alto carácter ético-moral².

El código profesional representa una de- claración formal del rol moral de los miembros de la profesión, especificando también reglas de etiqueta y responsabilidades internas. En la organización social moderna, una profesión no renuncia al código normativo rector del ejercicio profesional, ya que la moral incluye más que obligaciones ${ }^{3}$. La evidencia de la necesidad de mejorar el código de ética médica se ha hecho necesaria debido a los propios avances técnico-científicos, tanto 
en las relaciones humanas, profesionales y sociales, además de la importancia de adecuar el código a las resoluciones y legislación vigente en el país.

La historia de la ética en la práctica médica ha estado presente desde el origen de la profesión, siendo parte de su desarrollo a lo largo de su historia, emergiendo con el principio hipocrático primum non nocere (primero, no hagas daño), en el que coloca los intereses de los pacientes siempre primero ${ }^{4}$. En la tradición médica, los propios profesionales describieron e inspeccionaron sus fundamentos de trabajo, haciendo recomendaciones e incluso nuevas pautas para regular sus propias acciones. Así, el papel de la ética médica es determinar las normas necesarias para el desempeño del profesional dentro del ámbito de la integridad.

En muchos casos, pueden surgir conflictos de una teoría o principio con otro en la vida del profesional de la salud, por lo que la mejor decisión a tomar será en beneficio del paciente. Junto al paciente, existen preocupaciones familiares que, a pesar de ser atendidas, no deben perjudicar al paciente. Por ello, es necesario mantener un clima de confianza profesional a través de la honestidad, ya que es la base de la toma de decisiones mutuas y la calidad del servicio.

Las definiciones propuestas en los códigos de ética profesional pueden variar entre diferentes países, pero en general, existen principios de respeto a la autonomía, beneficencia, no maleficencia y justicia, que se basan y fundamentan en la ética médica. Estos cuatro principios básicos de la ética médica forman la base para que los profesionales de la salud dirijan y mantengan las prácticas clínicas éticas en todas las circunstancias ${ }^{5}$.

De los cuatro elementos existentes, el principio de autonomía puede considerarse el más discutido en la literatura ética, al referirse a la relación médico-paciente y la obtención del consentimiento informado. El término autonomía significa la capacidad de autogobernarse. Para que un individuo sea autónomo, es decir, capaz de tomar decisiones autónomas, es necesario que este individuo pueda actuar intencionalmente y tenga la libertad de actuar intencionalmente ${ }^{6}$.

Identificar las necesidades de cada paciente es fundamental para el éxito de cualquier tratamiento derivado de una buena relación entre médico y paciente. Es de destacar que las expectativas de cada individuo deben ser identificadas y respetadas, especialmente en los casos de denegación de tratamiento, donde el objetivo máximo alcanzado por el profesional debe ser la beneficencia, la obligación moral de actuar en beneficio del otro, y la preservación de intereses y el bienestar del paciente ${ }^{6}$.

El modelo bioético principialista es el marco teórico más adoptado en el mundo, y define la autonomía como el derecho del paciente a elegir sobre su propia vida y el deber del profesional de la salud de respetar esta autonomía; la no maleficencia, como deber del profesional de no causar pérdida o daño al paciente; y la justicia, como deber de distribuir los recursos de salud de manera equitativa ${ }^{7}$. Cuando un profesional de la salud promueve el alivio del dolor, se sigue el principio de beneficencia; por otro lado, si no lo trata, contribuye a la aparición de daño físico y psicológico, lesionando el principio de no maleficencia.

Teniendo en cuenta que la práctica de la medicina de vanguardia comienza con el reconocimiento de cuál es el procedimiento más eficaz para la atención al paciente, las decisiones que se toman para solucionar el problema del paciente suelen basarse en la aplicación consciente de información que puede ser evaluada mediante reglas explícitamente definidas. Toda la información entendida, independientemente de su veracidad, suele aplicarse en la práctica clínica, pero no es suficiente para describir e incluir el proceso tácito del juicio clínico.

La práctica clínica basada en la evidencia tiene en cuenta las necesidades de conocimiento explícito y tácito. La duda pasa a formar parte del proceso de decisión, inicialmente en la identificación de los componentes inconscientes involucrados, y en el análisis del conocimiento explícito utilizado en este proceso ${ }^{7}$. Por lo tanto, la medicina es mucho más que solicitar pruebas utilizando tecnología sofisticada o diagnóstico por imágenes.

Es necesario un cambio radical en este paradigma, es necesario que el profesional comience a evaluar las demás características de sus pacientes que no forman parte del contexto biológico. Estas personas pueden 
ser consideradas pacientes hipertensos, diabéticos y con enfermedades del corazón, pero más allá de eso, tienen un nombre, trabajan, se divierten, son padres, hermanas y tienen amigos. En beneficio de su calidad de vida, y no de un marcador biológico, el profesional de la salud debe orientar sus esfuerzos ${ }^{7}$. Es este cambio de paradigma el que ha perseguido la práctica clínica basada en la evidencia desde su lanzamiento en 1992.

Sabiendo que la ética investiga y explica las normas morales, en el contexto filosófico, la ética y la moral tienen significados diferentes. La ética está asociada al estudio fundamentado de los valores morales que guían el comportamiento humano en la sociedad, mientras que la moral son las costumbres, reglas y convenciones establecidas en cada sociedad ${ }^{1}$.

Por ello, esta presentación expone la necesidad de valores profesionales e institucionales en pos del bien individual y colectivo, capaces de vincular los principios colectivos a las concepciones personales a través de la moral y el entendimiento, requiriendo un proceso educativo que utilice la ética como método para incentivar el cambio conductual, responsable de la mejora de la educación médica en su conjunto.

\section{Bibliografía}

1. Fernando Q Monte. Ética Médica: Evolução Histórica E Conceitos. Revista Bioética (Impr). 2009; 17: 407-28. doi: 10.1590/0100-87977014006102.

2. Odilene U Nogueira, Marcus A Acioly. O Princípio Da Autonomia No Brasil: Discutir é Preciso. Revista Brasileira de Saúde Materno Infantil. 2014; 41: 274-77. doi: 10.1590/0100-69912014005013.

3. Francisco J P Soares, Helena e Shimizu, Volnei Garrafa. Código de ética médica brasileiro: Limites Deontológicos e Bioéticos. Rev Bioét (Impr). 2017; 25: 244-254. doi: 10.1590/1983-80422017252184.

4. Vergara P, García P. La ética médica en discusión: análisis de los clínica tratados en revistas nacionales de medicina y bioética 1998-2013. Acta Bioethica. 2017; 23: 71-81. doi: 10.4067/S1726569X2017000100071.

5. Raut S, Anand K. Medical ethics in clinical practice in nepal: challenges and way forward. Medical Education. 2018;18:69-72. doi: 10.3126/jucms. v6i2.22500.

6. Odile N Ugarte, Marcus André Acioly. O princípio da autonomia no Brasil: discutir é preciso. Rev Col Bras Cir. 2014; 41:274-77. doi: 10.1590/010069912014005013.

7. Souza L, Pessoa A, Barbosa MA, Pereira LV. O modelo bioético principialista aplicado no manejo da dor. Rev Gaúcha Enferm. 2013; 34:187-195. doi: 10.1590/S1983-14472013000100024. 